Наима Нефлямева

\title{
ЧТО ДЕЛАЕТ «ОСОБЕННЫМ» \\ ВЗРОСЛЕНИЕ НА СЕВЕРНОМ КАВКАЗЕ?
}

\section{Molodikova I., Watt A. (2014) Growing up in the North Caucasus: Society, Family, Religion and Education. London: Routledge. 224 p. ISBN978-0815369158.}

DOI: $10.17323 / 727-0634-2019-17-1-142-150$

В 2014 г. вышла книга Ирины Молодиковой и Алана Уотта «Взросление на Северном Кавказе: общество, семья, религия и образование». Оба автора - исследователи из Центрального Европейского университета в Будапеште. Судя по названию, книга обещала быть новаторским и актуальным исследованием. Несмотря на то, что указанные в названии исследовательские проблемы всегда присутствовали в кавказоведческой повестке (Смирнова 1983; Гатагова 1993; Малашенко 2001; Боров 2007), пока еще не существовало работы, которая бы объединила их в рамках одной монографии. Базовая идея книги-представить процессы воспитания молодежи на Северном Кавказе в широком контексте социализации в переходный для России и Кавказа период, а также исследовать, как молодые люди в XXI в. переходят к совершеннолетию, и выявить акторов, вовлеченных в процесс воспитания (семья, сообщество, религия, государственные институты). Авторы стремились донести до читателей «голос молодежи» из региона, т.е. проанализировать проблемы сквозь призму личных историй молодых северокавказских респондентов.

При работе над монографией авторами использовано семь различных типов источников: семь фокус-групп, проведенных в 2007 и 2012 г. с учителями в регионах СКФО и в Адыгее; 45 интервью с экспертами по проблемам школьного образования; семь фокус-групп со студентами, представителями каждой республики Северного Кавказа и Ставропольского края; анкетирование старшеклассников из Чечни, Северной Осетии, Ингушетии и Ставропольского края по теме «Обычаи и традиции в жизни моей семьи»; эссе, присланные на школьные конкурсы 14-18-летними подростками из Чечни, Северной Осетии и Ингушетии; интервью с представителями НКО; включенное наблюдение между 2009 и 2012 г.

Феномен, который авторы называют взрослением, является одной из традиционных тем кавказоведения. Основы его изучения заложены

Наима Аминовна Нефляшева- к.и.н., доцент, старший научный сотрудник Центра цивилизационных и региональных исследований, Институт Африки РАН, Москва, Россия. Электронная почта: innef@mail.ru 
еще дореволюционными исследователями Северного Кавказа, хрестоматийные труды которых, включая представителей горского просветительства (Леонтович 1882-1883; Ковалевский 1890; Хан-Гирей 1978; Миллер 1992), обязательны если не для детального изучения, то хотя бы для знакомства любого исследователя, берущегося за тему, связанную с современными процессами на Северном Кавказе. Обращение к классическим работамвозможность избежать иллюзий относительно собственных озарений и открытий, сделанных учеными XIX- начала XX вв. Исследования семьи, семейного воспитания, народной педагогики, школьного и высшего образования на Северном Кавказе было одной из востребованных тем и в советское, и в постсоветское время (Косвен 1963; Смирнова, ТерСаркисянц 1995; Бгажноков 2010; Магомедов 2010).

Однако авторы монографии избежали даже поверхностного знакомства с историей вопроса, а представленный ими историографический список работ, так или иначе выходящих на тему монографии, предельно скромен, насчитывает несколько фамилий и включает только труды 2000-х гг. Обращаясь к проблематике религиозных авторитетов в Дагестане, авторы обошлись без фундаментальной работы Энвера Кисриева «Ислам и власть в Дагестане» (2004). Незаслуженно обойден оказался и пионерский для своего времени труд Дмитрия Макарова «Официальный и неофициальный ислам в Дагестане» (2000).

В первой главе монографии дается обзор главных исторических событий в развитии образования в регионе с акцентом на постсоветский период. В первые постсоветские годы, справедливо отмечается авторами, экономическая стагнация и конфликты в регионе оказали влияние на деградацию качества образования. В условиях децентрализации расцветали местные языки и традиции, но отсутствие сильного государственного контроля привело к разрушению образовательной инфраструктуры и деморализации учителей. С конца 2000-х гг. государство предпринимает несколько модернизационных попыток для оживления образования, но еще не до конца ясно, подчеркивают авторы, насколько они будут успешны. Молодикова и Уотт считают, что недостаток профессионализма на всех уровнях системы образования и влияние клановой системы были главными проблемами при реализации постсоветской реформы образования в регионе.

Однако в этой в целом добротной обзорной главе не удалось избежать ошибок. Например, дано неверное определение политики коренизации. Она трактуется «как признание только 11 языков [русского и десяти кавказских] подходящими для получения образования» (Р. 25). Между тем, коренизация как составляющая советской национальной политики имеет гораздо более объемное наполнение. Профессор Гарвардского университета Терри Мартин назвал коренизацию «политикой положительной деятельности» и определил ее как «систематическое содействие развитию национального сознания этнических меньшинств и создание для них многих 
характерных институциальных форм моноэтнического государства» (Мартин 2011: 10). Коренизация на практике заключалась не только в языковом строительстве, но и в выдвижении представителей меньшинств на важные должности, формировании местных элит и создании национальных культур и институтов, обеспечивающих их функционирование.

Во второй главе анализируется вопрос доступа к качественному образованию на Северном Кавказе. С 2007 г., отмечают авторы, российское правительство предпринимало усилия, чтобы улучшить образование в СКФО и повысить престиж профессии учителя, в том числе за счет увеличения зарплаты, но эти преобразования идут очень медленно. Отсутствие надлежащего качества обучения часто связано с клановой системой, которая тормозит преобразования, повышающие престиж профессии учителя. Как отмечают авторы, учителя из всех обследованных регионов констатируют, что рост влияния религиозных семей на светское образование детей является фактором, характерным для всех конфессий на $\mathrm{Ce}$ верном Кавказе в первой половине 2010-х. Многие религиозные семьи ограничивают своих детей в участии в школьном процессе и внешкольной активности, препятствуя их нормальной социальной жизни и возможностям быть активными гражданами своей страны. За констатацией данного факта, с которым трудно не согласиться, хотелось бы видеть основаниясуществует ли статистика, касающаяся случаев такого влияния, и в чем конкретно оно проявляется? Для каких городов или сел это типично? Действительно, риск изоляции от образования для детей из очень религиозных семей тесно связан с риском религиозного оправдания молодежной воинственности, что является, по мнению авторов, реальностью для КБР, Чечни, Ингушетии и Дагестана. Религиозные и гендерные проблемы тесно связаны, и рост религиозности ведет к увеличению числа девочек, чьи родители не одобряют их обучение в школе.

В третьей главе авторы приходят к выводу, что на Северном Кавказе в последние 20 лет быстро развивается религиозность, и сегодня она является чрезвычайно важным фактором в жизни большинства детей. Исследователи справедливо указывают, что качество предлагаемого религиозного образования не соответствует масштабу его распространения. Религиозное образование в мусульманских сообществах на Северном Кавказе начинается на уровне семьи: дети начинают учить ритуалы и молитвы в раннем детстве, посещать праздники и готовиться к ним под руководством матерей, а в юности они уже принимают активное участие в религиозной жизни своего джамаата. Однако родители имеют ограниченные возможности контролировать религиозное образование детей на более продвинутых стадиях, потому что сами испытывают нехватку религиозных знаний. Отсутствие квалифицированных светских учителей, соответствующих учебников и методической литературы ослабляет эффективность государственных инициатив по религиозному образованию. Не вызывает возражений идея 
авторов о том, что низкое качество религиозного образования является фактором риска для развития экстремизма. Хотя кажутся недостаточными аргументы в пользу того, что конкуренция внутри духовного «сословия» за позиции на религиозном рынке труда вместе с нехваткой светского образования среди молодежи создает риск радикализации.

В четвертой главе авторы рассуждают о том, каков современный баланс между традиционными и модерными подходами в воспитании, а также насколько модернизация затронула семейную жизнь в целом. Анализ проблем воспитания в семье, основанный на результатах фокус-групп, показал, что Кавказ является фрагментированным и слабомодернизированным регионом. Социальная система цементируется консервативными семейными ценностями и иерархией, основанной на верховенстве мужчины и патриархатной структуре. Молодежь в регионе поддерживает традиционные ценности большой семьи не в самую последнюю очередь потому, что видит в ней источник поддержки. С другой стороны, влияние процессов модернизации состоит в том, что молодые люди пытаются делать личный, не зависящий от старших родственников выбор при решении жизненных вопросов, особенно в городах и в случае миграции в российские регионы.

В ходе написания данной главы авторам, к сожалению, не удалось избежать неточностей и ошибок. Они пишут, что полигамия сейчас возможна в Ингушетии, Чечне и Дагестане, где второй брак оформляется по шариату (Р. 102). На самом деле, полигамия возможна в любом регионе Северного Кавказа, она не признается государством, но ни в одной из республик нет никаких препятствий для заключения второго брака имамом с условием выполнения всех шариатских норм. Другое дело, что в таких республиках, как Адыгея, РСО-Алания, КБР и КЧР полигамия не получила общественного одобрения (Дзуцев, Смирнова 1993; Текуева 2006; Нефляшева 2013) и распространения, хотя единичные случаи встречаются и там.

Пятая глава посвящена анализу роли обычаев и традиций в воспитании. Авторы приходят к выводу, что возрождение некоторых традиций, ранее латентных и подавленных, идет в тандеме с возрождением шариата. Один из параграфов посвящен обряду умыкания невесты. Авторы пишут, что «после 1991 г. возрождение традиций в этнических республиках вместе с ростом свободы и потерей государственного контроля в некоторых частях региона привело к возрождению умыкания в повседневной практике» (Р. 110). На самом деле практика умыкания никогда не была полностью искоренена, несмотря на то, что власти последовательно и целенаправленно с ней боролись (Меретуков 1987). Следует при этом иметь в виду, что различаются два вида умыкания - фиктивное и реальное. К первому молодые люди прибегают по договоренности с девушкой в случае несогласия родителей на брак или из-за слишком высокой суммы калыма. Второй вид умыкания, когда оно совершается с применением насилия и без согласия девушки, давно вызывал неприятие в кавказских 
обществах, вырабатывавших различные меры противодействия этому явлению, вплоть до остракизма виновных в таком деянии. Поэтому авторам следовало бы добавить, что в 1990-е гг. возродилась не практика похищения невест сама по себе, а возросло число реальных (насильственных) похищений, преподносимых как умыкание (Новые известия 2007). Глава Чечни Рамзан Кадыров (Ибрагимов 2010) и глава Ингушетии Юнус-Бек Евкуров (Евкуров 2013) последовательно выступали против фиктивного и особенно против насильственного умыкания девушки, оценивая его в современных юридических категориях как уголовное преступление. Логично было бы также указать, что на Северном Кавказе различаются калым и махр. Калым как адатная норма- это символическая плата семье невесты за ее воспитание, а выплата махра-это шариатская норма, и эти деньги и имущество являются собственностью жены на случай ее вдовства или развода. В этой связи утверждение авторов о «плате за невесту (калым) по исламской традиции» (Р. 180) само по себе отражает непонимание базовых для Северного Кавказа явлений.

В шестой главе, на мой взгляд, самой удачной, авторы попытались представить некоторые маркеры «кавказскости», чтобы понять, как молодые люди из региона воспринимаются извне. Рост кавказофобии и частые конфликты между кавказцами и русскоязычной молодежью исследуются авторами в аспекте самопрезентации молодых кавказцев. Авторы утверждают, что в ходе фокус-групп не обнаружили каких-либо признаков агрессии именно к русским: скорее, следует говорить об агрессии к любому «другому» независимо от его личности. Анализ поведения кавказских молодых мужчин показывает, что их показная маскулинность воспроизводится по-разному в различных территориальных контекстах: дома, в других регионах России и за границей. Современная кавказская идентичность, как показывают авторы, манифестируется через такие символы и маркеры, как исполнение лезгинки, проявления сексуальности в отношении «других» девушек и пр. Анализ описанных участниками фокус-групп идеальных образов кавказских мужчины и женщины показал, что молодежь региона живет одновременно в традиционном, индустриальном и постиндустриальном обществе. Все информанты говорят, что ситуация перестает соответствовать идеалу патриархатной традиции, она более гибка на практике.

В седьмой главе представлены главные тревоги и надежды молодежи СКФО и анализируется отношение участников фокус-групп к различным инициативам государства по улучшению ситуации с молодежью на $\mathrm{Ce}$ верном Кавказе в последние годы. Авторы выделяют три причины недовольства студентов. Первая - это угроза экстремизма и насилия в регионе, которая беспокоит студентов в том числе и потому, что негативно влияет на восприятие региона извне, так что кавказская молодежь рассматривается в других регионах России как «граждане второго сорта» и «объект подозрений». Вторая проблема- это слабое качество образования в регионе, 
что заставляет молодежь чувствовать неспособность конкурировать на рынке рабочих мест. Третья проблема- недостаточное участие молодежи в принятии государственных решений: в регионе со строгими геронтократическими традициями молодежь чувствует отчужденность и исключенность из политических процессов, что является фактором, способствующим росту воинственности и экстремизма.

Авторы показывают различия между группами студентов по их отношению к идее многонационального государства. Студенты из республик, в которых преобладает мусульманское население, продемонстрировали большее желание интегрироваться в русскоговорящее окружение и мечту о гармоничном «безнациональном» государстве. Студенты из Северной Осетии и русские студенты, напротив, склонялись в пользу раздельного развития различных этнических групп, выражая страх быть поглощенными мусульманской культурой на Кавказе.

В данной главе авторы также обращаются к очень важной для Кавказа практике «мягкой силы» и теме учрежденных в 2010-е гг. в некоторых республиках Северного Кавказа комиссий по адаптации (ошибочно указав, что они созданы по всему Северному Кавказу), полное название которых«Комиссии по оказанию содействия в адаптации к мирной жизни лицам, решившим прекратить экстремистскую и террористическую деятельность». К сожалению, за пределами внимания остались другие судьбоносные инициативы властей, религиозных авторитетов и общества Дагестана на пути к внутриконфессиональному диалогу. Назову съезд народов Дагестана в 2012 г., учреждение «Ассоциации ученых Ахлю-Сунна в Дагестане», взаимное постановление суфиев и салафитов добиваться решения спорных вопросов путем научных дискуссий.

В заключении утверждается, что Кавказ развивается между традиционным и модерным вектором и на фоне миграционных процессов. Авторы указывают, что в 1990-е гг. на Кавказе в условиях резкого ослабления роли государства имела место архаизация. Люди обратились к религии, кланам и своим этническим группам как к источникам поддержки. Эти три актора сегодня, по мнению авторов, играют определяющую роль в воспитании ребенка на Кавказе, ограничивая монополию школы, существовавшую в советский период. Не вполне могу согласиться с утверждением о мнополии советской школы, поскольку даже в советский период большая семья в воспитании ребенка если не конкурировала со школой, то играла заметную роль, особенно в селах (Косвен 1963; Смирнова, Тер-Саркисянц 1995; Бгажноков 2010). В связи с этим Молодикова и Уотт выделяют три источника потенциальных проблем для российского государства на Северном Кавказе: тяга к религии может обернуться экстремизмом и воинственностью; лояльность клану генерирует коррупцию и непотизм; гордость за этническую идентичность ведет к ксенофобии. Концепция российской гражданской нации, как следует из проведенного 
исследования, не находит значительного отклика на Северном Кавказе. Ключевой подход, который предлагают авторы для противостояния радикализации мусульманской молодежи, заключается в том, чтобы направить энергию религии на созидательные цели, рассматривая ислам и мусульман не как часть проблемы, а как часть ее решения.

В целом монография производит неоднозначное впечатление. С одной стороны, проделана большая работа, опрошены сотни людей. С другой стороны, полученные результаты помещены в контекст региона, плохо знакомого авторам работы. Как следствие, для англоязычного читателя, впервые обращающегося к кавказской проблематике, монография создает образ региона, не соответствующий реальному, без полутонов и нюансов. Что касается выводов, то практически все они давно озвучены учеными и даже в большей степени журналистами и правозащитниками.

\section{Список источников}

Бгажноков Б. Х. (2010) Социальная организачия семьи. Нальчик: КБИГИ.

Боров А.Х. (2007) Северный Кавказ в российском иивилизачионном процессе (проблема социально-культурного синтеза). Нальчик: Кабардино-Балкарский гос. ун-т.

Гатагова Л.С. (1993) Правительственная политика и народное образование на Кавказе в $X I X$ в. М.: Россия молодая.

Дзуцев Х. В. Смирнова Я. С. (1993) Жизнь осетинской семьи (Этносоииологический acnекm). Владикавказ: Газетно-журнальная типография.

Евкуров Ю. Б. (2013) Кража невесты - это преступление. Доступно по ссылке: https://evkurov.livejournal.com/123375.html (дата обращения: 1 июня 2018).

Ибрагимов М. (2010) В Чечне похищение невест будет караться финансово и уголовно. Доступно по ссылке: http://www.kavkaz-uzel.eu/articles/175120/ (дата обращения: 1 апреля 2018).

Кисриев Э. Ф. (2004) Ислам и власть в Дагестане. М.: ОГИ.

Ковалевский М.М. (1890) Закон и обычай на Кавказе. Т. І- II. М.: Типография Мамонтова и Ко.

Косвен М.О. (1963) Семейная община и патронимия. М.: АН СССР.

Леонтович Ф.И. (1882-1883) Адаты кавказских гориев. Материаль по обычному праву Северного и Восточного Кавказа. Вып. 1-2. Одесса: Типография Зеленаго.

Магомедов А.М. (2010) Золотые правила народной педагогики Дагестана: этнографическое наследие гориев Северного Кавказа. Махачкала: Дагестанское книжное изд-во.

Макаров Д.В. (2000) Офищиальный и неофициальный ислам в Дагестане. М.: ЦСиПИ. Малашенко А. В. (2011) Исламские ориентиры Северного Кавказа. М.: Гендальф.

Мартин Т. (2011) Империя «положительной деятельности». Нации и национализм в СССР, 1923-1939. М.: РОССПЭН. 
Меретуков М.А. (1987) Семья и брак у адыгских народов. Майкоп: Адыгейское отделение Краснодарского книжного издательства.

Миллер В. Ф. (1992) Осетинские этюды. ч. I- III. М.: Северо-Осетинский институт гуманитарных исследований.

Нефляшева Н.А. (2013) Что на восточном Кавказе-тыл, то на западном-фронт. Еще о многоженстве... Доступно по ссылке: https:/www.kavkaz-uzel.eu/blogs/1927/ posts/13683 (дата обращения: 27 сентября 2018).

Новые известия (2007) Похищения невест становятся наииональным бедствием. Доступно по ссылке: https://www.newsru.com/crime/19oct2007/krazha_nevest.html (дата обращения: 9 сентября 2018).

Смирнова Я.С. (1983) Семья и семейный быт народов Северного Кавказа. Вторая половина $X I X-X X$ вв. М.: Наука.

Смирнова Я.С., Тер-Саркисянц А.Е. (1995) Народы Кавказа. Семья и семейный быт. Кн. 3. М.: ИЭИА.

Текуева М.А. (2006) Мужчина и женщина в адыгской культуре: традиции и современность. Нальчик: Эль-Фа.

Хан-Гирей (1978) Записки о Черкесии. Нальчик: Эльбрус.

Naima Nefljasheva

\section{WHAT MAKES GROWING UP IN THE NORTH CAUCASUS SPECIAL?}

Molodikova I., Watt A. (2014) Growing up in the North Caucasus: society, family, religion and education. London: Routledge. 224 P. ISBN978-0815369158

DOI: $10.17323 / 727-0634-2019-17-1-142-150$

\section{References}

Bgazhnokov B. Kh. (2010) Sotsialnaya organizatsiya semi [Family’s Social Organization]. Nalchik: Izdatelskiy otdel KBIGI.

Borov A. Kh. (2007) Severnyy Kavkaz v rossiyskom tsivilizatsionnom protsesse (problema sotsialno-kulturnogo sinteza) [North Caucasus in the Russian Civilization Process (the Problem of Socio-Cultural Synthesis)]. Nalchik: Kabardino-Balkarskiy gos. un-t.

Gatagova L. S. (1993) Pravitelstvennaya politika i narodnoye obrazovaniye na Kavkaze v XIX v. [Government Policy and Public Education in the Caucasus in XIX Century]. Moscow: Rossiya molodaya.

Naima Nefljasheva- $\mathrm{PhD}$ (kandidat nauk) in history, Senior researcher of Center for civilization and regional studies, Institute for African Studies, Russian Academy of Science, Moscow, Russian Federation. Email: innef@mail.ru 
Dzutsev Kh.V. Smirnova Ya.S.(1993) Zhizn osetinskoy semi (Etnosotsiologicheskiy aspekt) [Life of the Ossetian Family (Ethnosociological Aspect)]. Vladikavkaz: Gazetno-zhurnal'naya tipografiya.

Evkurov Yu.B. (2013) Krazh anevest-eto prestupleniye [The Kidnapping of Brides is a Crime]. Available at: https://evkurov.livejournal.com/123375.html (accessed 1 May 2018).

Ibragimov M. (2010) V Chechne pokhishcheniye nevest budet karatsya finansovo I ugolovno [In Chechnya Bride Kidnapping will be Punished Financially and Criminally]. Available at: http://www.kavkaz-uzel.eu/articles/175120/ (accessed 1 April 2018).

Kisriev E. F. (2004) Islam ivlast'v Dagestane [Islam and Authorities in Dagestan]. Moscow: O.G.I.

Kovalevskiy M. M. (1890) Zakon i obychay na Kavkaze [Law and Custom in the Caucasus]. Vol. I- II. . Moscow: Mamontov \& Co.

Kosven M.O. (1963) Semeynaya obshchina i patronimiya [Family Community and Patronymic]. Moscow: Akademiia Nauk SSSR.

Leontovich F. I. (1882-1883) Adaty kavkazskikh gortsev. Materialy po obychnomu pravu Severnogo i Vostochnogo Kavkaza [Adats of the Caucasian Highlanders: Materials on Customary Law of Northern and Eastern Caucasus]. Vol. 1-2. Odessa: Tipografiya Zelenago.

Magomedov A. M. (2010) Zolotyye pravila narodnoy pedagogiki Dagestana: etnograficheskoye naslediye gortsev Severnogo Kavkaza [The Golden Rules of Folk Pedagogy of Dagestan: The Ethnographic Heritage of the Highlanders of the North Caucasus]. Makhachkala: Dagestanskoye knizhnoye izd-vo.

Makarov D. V. (2000) Oficial'nyjineoficial'nyj Islam v Dagestane [Official and Unofficial Islam in Dagestan]. Moscow: CSaPS.

Malashenko. A.V. (2001) Islamskiye oriyentiry Severnogo Kavkaza [Islamic Orientation Points of North Caucasus]. Moscow: Gendalf.

MartinT. (2011) Imperija 'polozhitel'nojdejatel'nosty'. Naciiinacionalizm v SSSR, 1923-1939

[The Affirmative Action Empire: Nations and Nationalism in the Soviet Union, 1923-1939]. Moscow: ROSSPEN.

Meretukov M. A. (1987) Semia i brak u adygskikh narodov [Family and Marriage Among the Adyg Peoples]. Maykop: Adygeyskoe otdelenie Krasdodarskogo knizhnogo izdatel'stva.

Miller V.F. (1992) Osetinskiye etyudy [Ossetian Etudes]. Vol. I- III. Moscow: Severo-Osetinskiy institute gumanitarnykh issledovaniy.

Nefljasheva N.A. (2013) Chto na vostochnom Kavkaze-tyl. to na zapadnom-front. Eshche o mnogozhenstve... [That in the Eastern Caucasus-Rear, then in the Western-the Front. More about Polygamy]. Available at: https://www.kavkaz-uzel.eu/blogs/1927/posts/13683 (accessed 7 September 2018).

Novyye izvestiya (2007) Pokhishcheniya nevest stanovyatsya natsionalnym bedstviyem [Bride Abductions are Becoming a National Disaster]. Available at: https://www.newsru.com/crime/19oct2007/ krazha_nevest.html (accessed 9 September 2018).

Smirnova Ya.S. (1983) Semia i semeynyy byt narodov Severnogo Kavkaza. Vtoraya polovina $\mathrm{XIX}-\mathrm{XX} v v$. [Family and Family Life of the Peoples of the North Caucasus. Second Half XIX$\mathrm{XX}$. Moscow: Nauka.

Smirnova Ya.S.. Ter-Sarkisyants A.E. (1995) Narody Kavkaza. Semia i semeynyy byt [The Peoples of the Caucasus. Family and Family Life]. Vol. 3. Moscow: IEIA.

Tekuyeva M. A. (2006) Muzhchina i zhenshchina v adygskoy kulture: traditsii i sovremennost. [A Man and a Woman in the Adyg Culture: Traditions and Modernity]. Nalchik: El-Fa.

Khan-Girey (1978) Zapiski o Cherkesii [Notes on Cherkessia]. Nalchik: Elbrus. 